${ }^{I}$ Universidade do Estado do Rio de Janeiro (Uerj),

Rio de Janeiro, RJ, Brasil

giucci@uol.com.br

Guillermo Giucci'

\title{
CIDADE E CULTURA NA AMÉRICA DO SUL
}

\author{
Ciudades sudamericanas como arenas culturales. \\ Adrián Gorelik \& Fernanda Arêas Peixoto (compiladores). \\ Buenos Aires: Siglo Veintiuno Editores, 2016.
}

Recordo nitidamente quando conheci Richard Morse. Foi na Universidade de Stanford, em I980. Uma espécie de halo mítico o nimbava. A variada trajetória como estudioso da América Latina - havia vivido em Cuba, Porto Rico, Chile, Argentina, Brasil, Haiti - e seus pioneiros estudos urbanos, em particular seu livro De comunidade à metrópole: a biografia de São Paulo, fazem dele uma referência obrigatória. Já nesse primeiro encontro com Morse, assim como em outros posteriores, me chamaram a atenção a sua paixão pelo objeto de estudo, seu vasto conhecimento, seu caráter expansivo. Parecia que o escritório, repleto de livros, não poderia contê-lo, por ser demasiado pequeno para acomodar esse historiador original e ensaísta norte-americano de horizontes dilatados.
Essa qualidade expansiva e reflexiva é uma das muitas virtudes do livro Ciudades sudamericanas como arenas culturales, compilado pelo arquiteto e historiador argentino Adrián Gorelik e a antropóloga brasileira Fernanda Arêas Peixoto. Arenas culturales, no título, rende homenagem à obra de Richard Morse, em particular o artigo, “Cidades 'periféricas' como arenas culturais", de i982. Significa que a cidade como espaço público, em sua dupla vertente de visão e ação, é simultaneamente o foco da experimentação cultural e o lugar de enfrentamento de ideias. O que a América Latina costuma chamar de vida cultural moderna, argumentam Gorelik e Peixoto, se opera principalmente na cidade.

A pesquisa, que reúne cidade e cultura, se apoia menos na abordagem 
socioeconômica que na combinação da "virada cultural" urbana com a "virada espacial" das ciências sociais. Uma grande contribuição do livro consiste em privilegiar a perspectiva urbana da história cultural, a partir de uma estrutura comparativa e de ângulos distintos da pesquisa universitária (história, arquitetura, crítica literária, antropologia, sociologia, filosofia). Trata-se de um verdadeiro trabalho coletivo: anos de debate e pesquisa em grupo; 23 artigos e 25 autores; análises de momentos emblemáticos, fragmentos espaciais, circuitos intelectuais, produções letradas e da cultura popular e de massa, programas governamentais, institucionais e urbanísticos.

Embora os artigos sejam considerados ensaios e experimentos de uma aproximação metodológica que destaca a diversidade em vez de uma teoria unitária, todos eles, sem exceção, se apoiam em uma multiplicidade de notas de pé de página e de referências bibliográficas. Não são, portanto, produto de um espírito polêmico que falta à tradição formal e que não satisfaz as exigências acadêmicas. Por outro lado, se tais artigos se aproximam da ideia de "ensaio como forma", de Theodor Adorno, é devido à capacidade de conseguir que a totalidade brilhe no fragmento, mas sem afirmar sua presença.

De modo geral, o contexto teórico não é explícito. Os artigos se desenvolvem livres da subordinação a uma corrente ideológica única, sejam os estudos culturais britânicos, seja o pós-estruturalismo sociológico, seja a micro-história, sejam os estudos de gênero e pós-coloniais. Predominam a abordagem histórica e o olhar a cidade como texto. Ocasionalmente surgem resquícios da tradicional história política e social. Em outros casos se investiga a relação entre as formas culturais de elite e as populares, culturas centrais e periféricas, rupturas e continuidades em processo de modernização cultural das cidades na América do Sul.

Tampouco são enfatizados os conceitos instrumentais de planificação, dissolução, recuperação. Ao contrário, "moderno" e "processo de modernização" são conceitos-chave. A variedade de temas e enfoques desemboca em análises de processos de modernização específicos na América do Sul, que dão lugar a eclosões do moderno, seja na experiência familiar ou individual da cidade, seja das "margens" urbanas ou da cidade como imagem contrária ao campo.

Embora a perspectiva sul-americana manifeste-se ousada quando a informação disponível para cada localidade é diferente, oferece inegáveis atrativos. Questiona-se a tendência dos estudos urbanos restringidos a enquadramentos específicos que raramente ultrapassam as barreiras nacionais. Tal situação responde à falta de redes entre investigadores e à localização das fontes para pesquisa em arquivos e bibliotecas nacionais. Dentro do território sul-americano existem diferenças no volume de documentação disponível. Grande parte da investigação desenvolvida, até hoje, sobre temas da história urbana se encontra concentrada no Brasil, Argen- 
tina, Uruguai e Chile. Menos cobertas estão as cidades principais do Peru, Bolívia, Equador, Venezuela, Colômbia e Paraguai.

Essa diferença reflete-se na organização cronológica e distributiva do livro (Laboratórios culturais; O novo I 9 Io-I930; Cenas de modernização I940-I970; Cenas partidas I940-I970; Espetáculos urbanos I990-20I0). Se bem que o projeto não pretenda lograr um efeito representativo, cidades como Buenos Aires, Rio de Janeiro, São Paulo e Montevidéu são examinadas em diferentes momentos históricos, enquanto Lima, Quito, Bogotá e Caracas são contempladas com um momento histórico singular e se descartam capitais como La Paz e Assunção em favor de cidades como La Plata, Córdoba, Salvador, Recife. Enfrentamos aqui limites práticos do projeto comparativo. Contudo, nesse caso, o livro Ciudades sudamericanas como arenas culturales se mostra de sumo interesse. Não somente estabelece um vínculo estrutural entre cidade e cultura, mas, também, investiga formas novas de convocar o enfoque comparativo.

A noção de "cultura", entendida em sentido amplo, atua como princípio metodológico e epistemológico. Superada a definição normativa e orientada pela concepção particularista que pensa a diferença cultural, a seleção das cidades desfaz o critério hierárquico. Cada cidade examinada possui valor próprio, que é adicionado ao mapa comparativo. La Plata, Córdoba e Recife coexistem com Buenos Aires e São Paulo. As figuras culturais do novo na cidade do bosque (La Plata), a refor- ma de igr 8 (Córdoba) e a cidade da infância de Gilberto Freyre (Recife) convivem com a gíria e a cultura urbana em Buenos Aires e com o edifício Martinelli e a euforia vertical em São Paulo entre os anos igio e i930. Cidades tão diferentes como Salvador e Brasília se conjuntam a Bogotá e Caracas entre os anos I940 e I970. Nesse mesmo período, a capital Quito, com suas ruas congestionadas, da modernidade e do mundo popular dos Andes, os projetos para os bairros de Lima e a "capital da esquerda" (Santiago de Chile) coabitam com Montevidéu, cuja ânsia de ser cosmopolita se via desviada por uma crise econômica emergente e pelas retóricas do passado e futuro entre o campo e a cidade.

Os três artigos sobre Rio de Janeiro são um exemplo das mudanças temporais e espaciais. O Rio de Janeiro da Belle Époque centra-se nas irradiações de uma rua, a famosa rua do Ouvidor. Em seguida se examina um bairro. Copacabana, a "princesa do mar", é na década de 1950 o lugar para onde convergem o cosmopolitismo, a nação e a modernidade. Posterior à transferência da capital para Brasília em I960 esse excepcional experimento modernista no sertão que, em palavras de Ángel Rama, constituiu o "mais fabuloso sonho da urbe de que foram capazes os americanos" -, o Rio de Janeiro é analisado como cidade midiática. Perde importância política (feito que é expressado simbolicamente quando o presidente Juscelino Kubitschek fecha os portões do Palácio do Catete, sede até então pertencente ao Poder Executivo federal), contudo adquire influência nacional e internacional 
nas novelas da rede Globo. Avenida Brasil, a novela que se refere à vida no subúrbio e mais especificamente ao bairro de Madureira, da zona norte do Rio de Janeiro, foi exibida em mais de I 25 países e teve êxito contundente na Argentina.

Algo semelhante sucede com Buenos Aires e São Paulo, cidades que compõem, cada uma, quatro artigos. Buenos Aires vai desde cidade da boemia e da vida literária oitocentista para cenário de mescla de idiomas dos portenhos e a viagem das palavras; da denúncia da cidade dual partida - avenidas burguesas contra as vilas de miséria - ao estudo dos festivais e transformações urbanas concentrados no exemplo do Buenos Aires Festival Internacional de Cine Independente (Bafici), inaugurado em I 999 no bairro El Abasto até a mudança da sede em 2013 para a Village Recoleta, e que implicou a renúncia definitiva ao equilíbrio urbano-cultural.

São Paulo, a cidade sul-americana que hoje mais se aproxima da definição de "cidade mundial" (veja-se o artigo do antropólogo sueco Ulf Hannerz O papel cultural das cidades mundiais), transita das disputas das elites na avenida Paulista da Belle Époque às ambivalências do moderno materializadas nos arranha-céus das formas arquitetônicas; do teatro e culturas urbanas dissidentes ao Teatro Oficina, instigadora arena cultural inaugurada em I 993 no bairro Bexiga.

Aspecto relevante do livro são as imagens em preto e branco que complementam o tecido textual, oferecendo densidade histórica e um sabo- roso condimento extra. Não se trata de imagens arbitrárias e decorativas, mas foram cuidadosamente selecionadas para ilustrar os textos: litografias antigas, desenhos e croquis; cartões-postais; fachadas de diários, posters e cartazes publicitários; vistas aéreas e planos urbanos; fotografias de festas populares, ruas, avenidas, palacetes, edifícios e favelas. Especialmente no caso das fotografias modernas, constata-se a presença de bondes de tração animal e elétricos, ônibus, camionetas, automóveis, incluindo uma reveladora foto de um periódico com o presidente da Venezuela levando Juan Manuel Fangio em seu automóvel Mercedes Benz. Talvez isso seja significativo da possibilidade de somar numa próxima investigação a chamada "virada da mobilidade", cujo fundamento teórico interacionista reside na aproximação dos fenômenos sociais como o estudo da mobilidade de pessoas, objetos e ideias.

O pensamento precursor de Richard Morse, atualizado e devidamente purgado de sua postura celebratória, se irradia no começo do século XXI, de modo implacável, sobre geografias materiais e simbólicas sul-americanas. Desde já texto de referência inevitável para os estudos urbanos, Ciudades sudamericanas como arenas culturales se converte também em modelo para prosseguir o trabalho coletivo na direção de uma reflexão sobre a virada cultural urbana da América Latina e a singular imbricação entre cidade e cultura.

Recebida em 09/03/20I7 | Aprovada em 20/03/20I7 
Guillermo Giucci é Ph.D. em letras pela Stanford University, leciona no Programa de Pós-Graduação em Letras da Universidade do Estado do Rio de Janeiro (Uerj). Foi professor visitante nas Universidades Albert-Ludwigs, Poitiers, Texas, Los Angeles, Stanford. Recebeu as bolsas Guggenheim e Tinker. É autor de Viajantes do maravilhoso: o Novo Mundo (I992); Sem fé, lei ou rei (I993); A vida cultural do automóvel (2004); Gilberto Freyre: uma biografia cultural (2007), com Enrique Rodríguez Larreta; Tierra del Fuego: la creación del fin del mundo (2014). 